\title{
Geometric Form of Gating System Elements and Its Influence on the Initial Filling Phase
}

\author{
Rafał Dojka, Jan Jezierski, and Niels Skat Tiedje
}

\author{
(Submitted October 3, 2018; in revised form January 22, 2019; published online March 11, 2019)
}

\begin{abstract}
Flow of cast steel through twenty-four variants of gating system was examined with the use of numerical modeling conducted in MAGMA. The main goal of the research was to determine the impact of the gating system elements' geometric form on the kinetics in the initial filling phase, which is crucial in terms of castings quality. The evaluation was based on flow kinetics, maximal height, and the velocity of metal entering the mold. The variables included the geometric form of the sprue and the cross runner, as well as geometric form, length, and expansion of the ingate. Results allow to form valuable conclusions that can lead to improvement in the castings manufacturing technology. Results show that application of proper expansion of the ingate and suitable geometric form of the gating system can significantly reduce the velocity of metal entering the mold cavity, as well as eradicate the jetting, which positively impacts the soundness of the casting.
\end{abstract}

Keywords cast steel, flow analysis, gating system, internal quality, simulation

\section{Introduction}

Cast steel is, without any doubts, an alloy with an established position in the casting manufacturing market (Ref 1-3). Undoubtedly, the geometric form of gating system has crucial influence on the mold filling process, which is one of the key components in ensuring proper quality of the casting (Ref 4-6). At the time when commonly used principles for gating system design were created (1950s and 1960s), the possibility to simulate the mold filling process was very limited in comparison with the present times (Ref 7-13). However, since then, the activity in the field of scientific research associated with the gating systems design has clearly decreased, and the rules formulated back then are still utilized. The majority of foundries still uses them in the process of designing manufacturing technology.

This article is an invited submission to JMEP selected from presentations at the 73rd World Foundry Congress and has been expanded from the original presentation. 73WFC was held in Krakow, Poland, September 23-27, 2018, and was organized by the World Foundry Organization and Polish Foundrymen's Association.

Rafal Dojka, Department of Foundry Engineering, Faculty of Mechanical Engineering, Silesian University of Technology, ul. Towarowa 7, 44-100 Gliwice, Poland; and Odlewnia Staliwa Łabędy, ul. Mechaników 9, 44-109 Gliwice, Poland; Jan Jezierski, Department of Foundry Engineering, Faculty of Mechanical Engineering, Silesian University of Technology, ul. Towarowa 7, 44-100 Gliwice, Poland; and Niels Skat Tiedje, Section of Manufacturing Engineering, Department of Mechanical Engineering, Technical University of Denmark, Produktionstorvet Building 425, Room 223, 2800 Kgs. Lyngby, Denmark. Contact e-mails: rafal.dojka@polsl.pl and jan.jezierski@polsl.pl.
In many steel foundries, utilization of prefabricated chamotte brickwork in order to construct a gating system is a common practice. The main advantages of these solutions include the possibility to reduce the number of parting planes and use the core, which allows to save time during molding and provides high thermal resistance. However, most of prefabricates come with circular cross section of the channel, which is characterized by the lowest ratio between perimeter and the area. Such channels minimize the friction of metal against the mold and have high potential for creation of turbulence (Ref 11). Foundries using gating systems, manufactured with the use of patterns, tend to use mostly trapezoid, rarely semicircle or triangular, shapes of cross runners. Again, in most cases, such shapes are characterized by low ratio between perimeter and the area. Authors believe that application of a proper shape of a cross runner may reduce velocity of metal and grant less turbulent flow. Of course, higher perimeter with the same crosssectional area would translate into higher area of heat transfer between metal and the mold, and, if improperly designed, such gating system could result in short-run casting. To account for this possibility, authors prepared a new tester (patent pending) which allows to measure the influence of increased perimeter of the runner on the fluidity. However, this tester will be the subject of further analysis. Traditional rules for gating system design discourage the use of ingates with expansion angle, because they might cause detachment of metal from the mold's wall and turbulence of the flow. Yes, it is true, however, only when the ingate is poorly designed.

Authors are convinced that it is highly important to take advantage of modern technology to reveal that gating system design can be improved, and often used rules are at most correct, and far from perfect or even optimal (Ref 14-18), and, at times, they may even cause casting defects instead of preventing them (Ref 19-25). Work presented by the authors is based on, and strictly connected with, the theories of prof. John Campbell, one of the most renown scientists in the field of gating system design. Authors follow general rules formulated by prof. Campbell (Ref 18), as they believe that their application can truly bring foundry engineering into the twenty-first century. 
Presented research, described in this article, is a part of a wide experimental plan, meant to develop a scientifically optimized and practically useful molding technology. In this article, authors want to present the influence of geometric form of the sprue, the cross runner, and the ingate on the flow kinetics in the initial filling phase of the mold.

\section{Methodology}

In order to analyze the differences in flow kinetics in each system, the authors prepared an experimental plan consisting of 24 simulations performed in MAGMASOFT MAGMA5. Two types of naturally pressurized sprue were compared. The first sprue was a variation of traditionally used tapered sprue with circular cross section (circular sprue); however, the tapering was not straight, but was changing according to the hyperbolic curve, together with the falling stream of metal resulting from the stream continuity law. The second sprue (transitional sprue) shape changed from circular cross section to rectangular cross section according to special shape transition, while the cross section surface reduction was analogous to the one in the first sprue. The first sprue was connected with a circular cross runner, while the second sprue was connected with a rectangular cross runner. The reason behind using rectangular cross runner was the fact that it was proven that application of runners with low height to width ratio contributes to less turbulent flow and the decrease in metal reoxidation (Ref 11, 18). In every variant, the cross runner was extended and ended with a spin trap, which allowed to successfully trap the first portion of cooled and oxidized metal and reduce the metal pressure in the system, and thus the velocity of the metal entering the mold. Examined ingates had circular and rectangular cross sections, different " $H$ " heights $(25$ and $50 \mathrm{~mm})$ and different " $\alpha$ " expansion angles $\left(0^{\circ}, 5^{\circ}\right.$, and $\left.10^{\circ}\right)$, as shown in Fig. 1, allowing to examine the possibility of reducing the metal injection effect without the detachment of the stream from the mold wall. In order to present the results in a transparent way, the systems were marked "regular" and "irregular" as shown in Table 1.

Each gating system with the same level of ingate expansion had exactly the same volume. Simulated alloy was GS-52 cast steel, according to DIN 1681, pouring temperature was set to $1570{ }^{\circ} \mathrm{C}$, and alphaset molding sand was used as the mold material. The "test casting" was a cuboid with dimensions of $60 \times 60 \times 100 \mathrm{~mm}$, the diameter of the ingate was $15 \mathrm{~mm}$, the diameter of circular cross runner was $13.2 \mathrm{~mm}$, and the dimensions of rectangular cross runner were equal to $23.5 \times 6 \mathrm{~mm}$. The average weight of the casting with the gating system was $5.2 \mathrm{~kg}$, while the metal output into the sprue

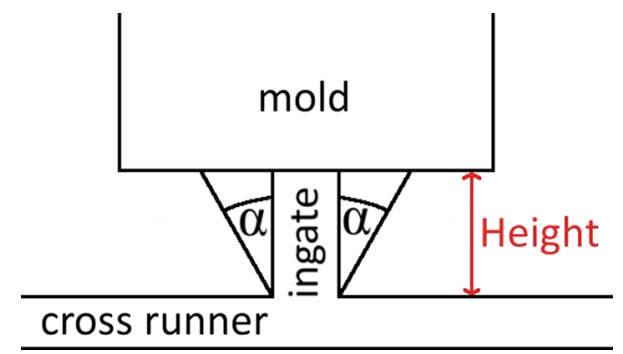

Fig. 1 Scheme of the geometric form of the used gating system was $3.3 \mathrm{~kg} / \mathrm{s}$. The mesh cube dimensions were $1.5 \times 1.5 \times 1.5 \mathrm{~mm}$, and the average number of cavity elements was 197,500. All simulated variants are presented in Table 2.

Obtained simulations allowed the assessment of each examined solution based on the flow kinetics, the metal mixing intensity, the presence of the jetting effect, height of the jet, and metals' velocity. Velocity measuring point was located in the center of mold cavity, $1 \mathrm{~mm}$ above the ingate. When the technological parameters, such as metallostatic pressure and geometric form of the gating system, are chosen correctly, the mold's initial filling phase should look as shown in Fig. 2(a). Metal which entered the mold has low ratio between vertical and horizontal velocities, which results in complete covering of the bottom surface of the mold, followed by rising of the metal surface, until the mold is completely filled. This way of filling allows to prevent reoxidation of metal inside the mold, as well as to avoid formation of oxide biofilms, where both dramatically deteriorate the mechanical properties of the castings. Figure 2(b) shows the improper initial phase during filling of the mold. Vertical velocity of the metal entering the mold is too high, which results in formation of the jet. In case of variants without the jetting, the " $h$ " height was measured as the height

Table 1 Nomenclature, regular, and irregular systems

\begin{tabular}{lcc}
\hline & $\begin{array}{c}\text { Circular cross } \\
\text { runner }\end{array}$ & $\begin{array}{l}\text { Rectangular } \\
\text { cross runner }\end{array}$ \\
\hline $\begin{array}{ll}\text { Circular ingate } \\
\text { Rectangular ingate }\end{array}$ & $\begin{array}{l}\text { Regular } \\
\text { Irregular }\end{array}$ & $\begin{array}{l}\text { Irregular } \\
\text { Regular }\end{array}$ \\
\hline
\end{tabular}

Table 2 Geometric form of examined gating system elements

\begin{tabular}{|c|c|c|}
\hline Sprue and cross runner & $\begin{array}{c}\text { Ingate, } \\
\text { expansion } \\
\text { angle }(\alpha)\end{array}$ & $\begin{array}{l}\text { Height } \\
(H), \mathrm{mm}\end{array}$ \\
\hline \multirow[t]{3}{*}{ Circular sprue, circular cross runner } & Circular, $0^{\circ}$ & $\begin{array}{l}25 \\
50\end{array}$ \\
\hline & Circular, $5^{\circ}$ & $\begin{array}{l}25 \\
50\end{array}$ \\
\hline & Circular, $10^{\circ}$ & $\begin{array}{l}25 \\
50\end{array}$ \\
\hline \multirow[t]{3}{*}{ Circular sprue, circular cross runner } & Rectangular, $0^{\circ}$ & $\begin{array}{l}25 \\
50\end{array}$ \\
\hline & Rectangular, $5^{\circ}$ & $\begin{array}{l}25 \\
50\end{array}$ \\
\hline & Rectangular, $10^{\circ}$ & $\begin{array}{l}25 \\
50\end{array}$ \\
\hline \multirow[t]{3}{*}{$\begin{array}{l}\text { Transitional sprue (circular to rectan- } \\
\text { gular), rectangular cross runner }\end{array}$} & Circular, $0^{\circ}$ & $\begin{array}{l}25 \\
50\end{array}$ \\
\hline & Circular, $5^{\circ}$ & $\begin{array}{l}25 \\
50\end{array}$ \\
\hline & Circular, $10^{\circ}$ & $\begin{array}{l}25 \\
50\end{array}$ \\
\hline \multirow[t]{3}{*}{$\begin{array}{l}\text { Transitional sprue (circular to rectan- } \\
\text { gular), rectangular cross runner }\end{array}$} & Rectangular, $0^{\circ}$ & $\begin{array}{l}25 \\
50\end{array}$ \\
\hline & Rectangular, $5^{\circ}$ & $\begin{array}{l}25 \\
50\end{array}$ \\
\hline & Rectangular, $10^{\circ}$ & $\begin{array}{l}25 \\
50\end{array}$ \\
\hline
\end{tabular}


of the stream covering the bottom surface of the mold, as shown to Fig. 2(a). When the jetting effect was present, the height of the jet shown in Fig. 2(b) was measured; note that it was at its maximum before the spin trap was completely filled, so the increased pressure in the system did not affect it.

\section{Results and Discussion}

The analysis of the conducted simulations allowed to obtain the results of the maximum height $(h)$ of the metal during the initial phase of mold filling, as shown in Table 3 and in Fig. 3,
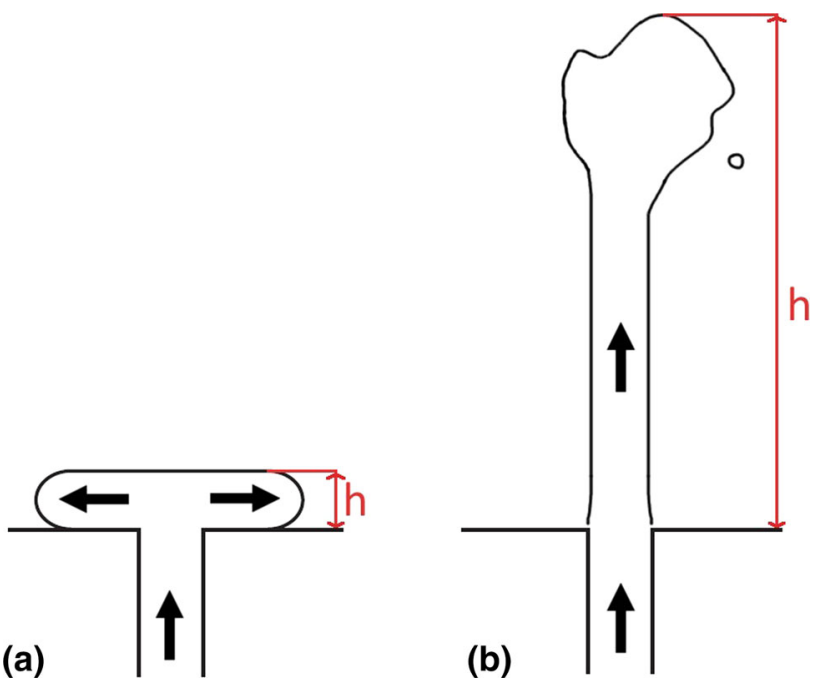

Fig. 2 Initial mold-filling phase without jetting effect (a) and with jetting effect (b) and the velocity (v) of metal entering the mold, as shown in Table 3 and in Fig. 4.

Analysis of regular circular variants showed that, in case of both tested $H$ heights, the increase in the ingate expansion angle resulted in a decrease in the jet height and velocity of the metal entering the mold cavity. In this variant, $H$ is one of the key factors, as it should be noticed that the ingate of $H=50 \mathrm{~mm}$, with no expansion, decreased the velocity to a value lower than the value achieved in case of the ingate of $H=25 \mathrm{~mm}$ with $\alpha=10^{\circ}$.

In case of regular rectangular variant, $H$ height of the ingate has a less significant impact on the reduction in $v$ and $h$. Nonexpanded ingates of $H=50 \mathrm{~mm}$ and $H=25 \mathrm{~mm}$ presented similar $v$ and $h$; however, in nearly all cases, with only a single exception, the expansion resulted in reduction in jetting and a significant decrease in $v$. In case of $H=25 \mathrm{~mm}$ and $\alpha=10^{\circ}$, we observed an increase in $v$ and $h$ values; however, they were lower compared to the values for $\alpha=0^{\circ}$.

Irregular circular into rectangular systems show relationship between $\alpha, v$, and $h$ similar to regular circular variants in all but one case. In case of $H=50 \mathrm{~mm}$ and $\alpha=10^{\circ}, v$ and $h$ values increased; however, they were lower compared to the values for $\alpha=0^{\circ}$. Results have shown that placing a rectangular ingate with its longer side parallel to the axis of a cross runner will generate this effect in most cases. This effect would contribute to turbulent flow, which would result in metal reoxidation, so this design should be avoided.

Irregular rectangular to circular variant of $H=25 \mathrm{~mm}$ results were similar to regular circular variant with the same $H$. The increase in expansion angle results in the slight decrease in $h$ and $v$. Expansion of $5^{\circ}$ and $10^{\circ}$ in this variant of $H=50 \mathrm{~mm}$ brought great reduction in $v$ and $h$.

Systems that presented the best ability to reduce the jet height and velocity of metal are regular rectangular systems, as they presented the lowest average $v$ and $h$. When they expand,

Table 3 Maximum height $(h)$ and the velocity $(v)$ of the metal during the initial phase of mold filling

\begin{tabular}{|c|c|c|c|c|c|}
\hline Type & Subtype (sprue and cross runner) & Height, mm & Ingates expansion angle $(\alpha)$ & $h, \mathrm{~mm}$ & $v, \mathbf{m} / \mathbf{s}$ \\
\hline \multirow[t]{12}{*}{ Regular } & Circular & 25 & $0^{\circ}$ & 72 & 1.72 \\
\hline & & & $5^{\circ}$ & 49 & 1.58 \\
\hline & & & $10^{\circ}$ & 38 & 1.40 \\
\hline & & 50 & $0^{\circ}$ & 34 & 1.35 \\
\hline & & & $5^{\circ}$ & 10 & 0.54 \\
\hline & & & $10^{\circ}$ & 4 & 0.35 \\
\hline & Rectangular & 25 & $0^{\circ}$ & 23 & 0.74 \\
\hline & & & $5^{\circ}$ & 1 & 0.27 \\
\hline & & & $10^{\circ}$ & 6 & 0.46 \\
\hline & & 50 & $0^{\circ}$ & 21 & 0.65 \\
\hline & & & $5^{\circ}$ & 1 & 0.24 \\
\hline & & & $10^{\circ}$ & 1 & 0.22 \\
\hline \multirow[t]{12}{*}{ Irregular } & Circular into rectangular & 25 & $0^{\circ}$ & 105 & 1.88 \\
\hline & & & $5^{\circ}$ & 71 & 1.66 \\
\hline & & & $10^{\circ}$ & 33 & 1.31 \\
\hline & & 50 & $0^{\circ}$ & 92 & 1.79 \\
\hline & & & $5^{\circ}$ & 35 & 1.26 \\
\hline & & & $10^{\circ}$ & 55 & 1.64 \\
\hline & Rectangular into circular & 25 & $0^{\circ}$ & 46 & 1.52 \\
\hline & & & $5^{\circ}$ & 41 & 1.45 \\
\hline & & & $10^{\circ}$ & 33 & 1.28 \\
\hline & & 50 & $0^{\circ}$ & 45 & 1.47 \\
\hline & & & $5^{\circ}$ & 1 & 0.23 \\
\hline & & & $10^{\circ}$ & 1 & 0.22 \\
\hline
\end{tabular}




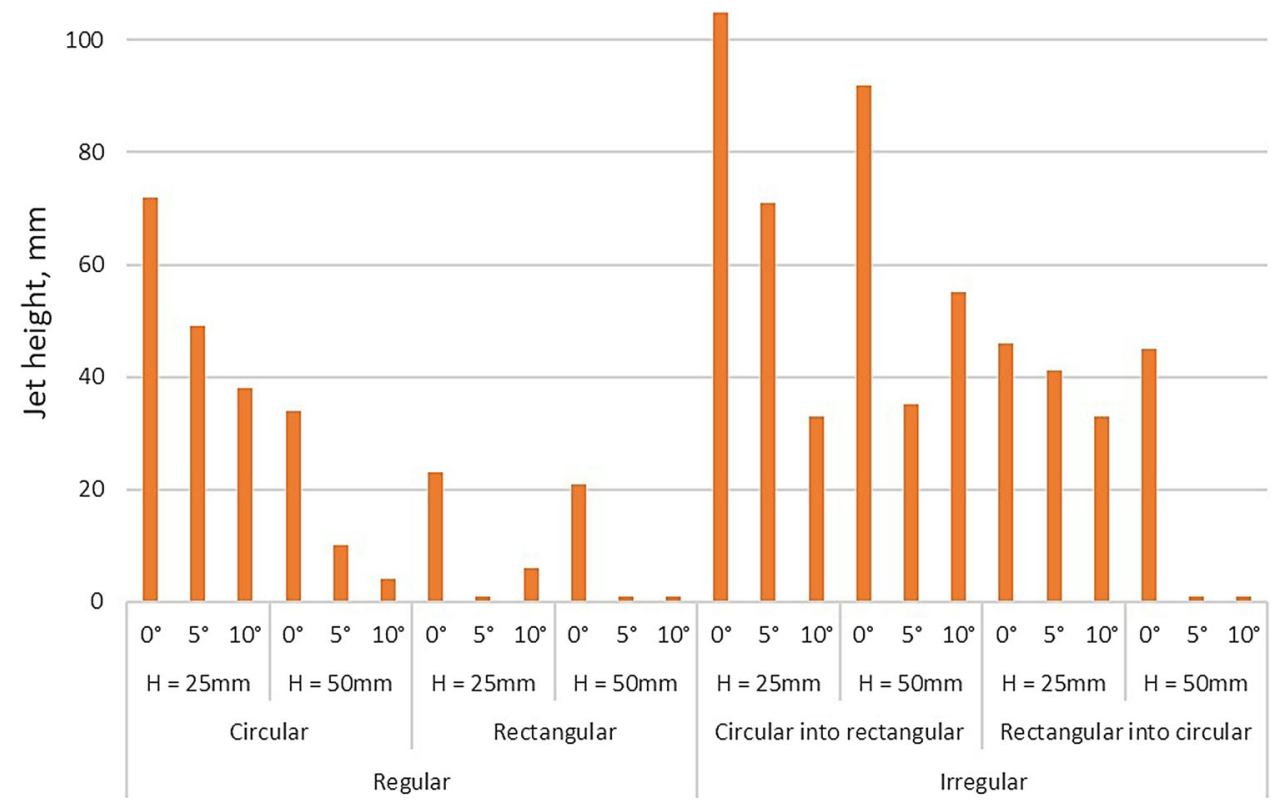

Fig. 3 Maximum height $(h)$ of the metal during the initial phase of mold filling

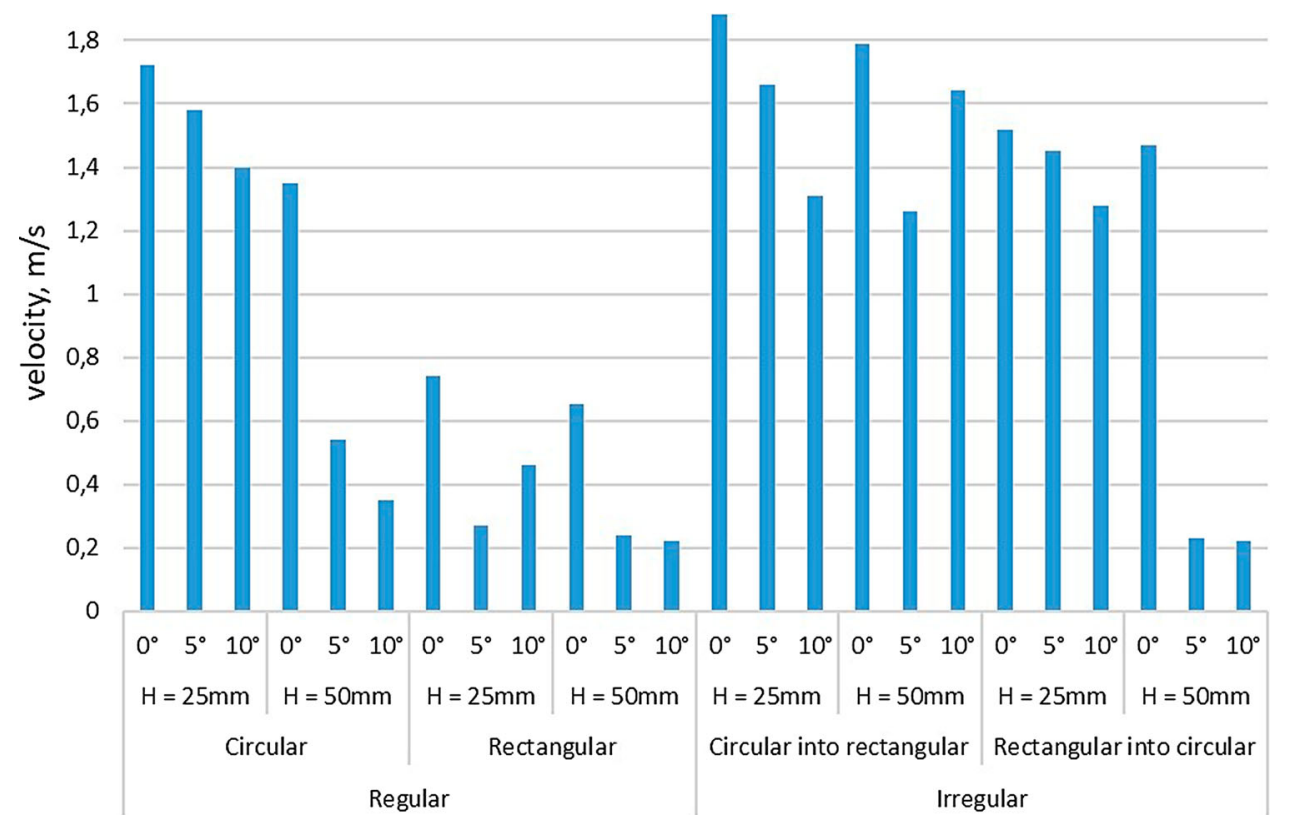

Fig. 4 Velocity $(v)$ of the metal entering the mold during the initial phase of mold filling

their $v$ decreases to values between 0.2 and $0.3 \mathrm{~m} / \mathrm{s}$, that is, an over $84 \%$ reduction in comparison with the highest obtained value, and the occurrence of jet is completely eliminated.

There are two other systems that could be recommended. The first one is a regular circular system of $H=50 \mathrm{~mm}$, with expansion, $\alpha=5^{\circ}$ that allows the reduction in velocity by $71 \%$ in comparison with the highest value, and by $81 \%$ in case of $\alpha=10^{\circ}$. The second one is the irregular rectangular into circular system of $H=50 \mathrm{~mm}$, as it reduced $v$ to the values higher than the values obtained using the regular rectangular system, but only in case of $\alpha=5^{\circ}$ and $\alpha=10^{\circ}$.

In most cases, along with the increase in the length of the ingate and with the increase in expansion angle, the height of the liquid metal, as well as its velocity during entering the mold, decreased and, in some cases, jetting was eliminated. Pearson's " $r$ " correlation coefficient calculation was executed for the parameters of " $v$ " velocity and " $h$ " height, $r_{\mathrm{vh}}=$ 0.9212, which indicates almost perfect correlation.

Perfect example of improper filling is shown in Fig. 5, which presents the regular circular system of $H=25 \mathrm{~mm}$. Liquid metal enters the mold, accompanied by a gusher-like effect, dripping, and splashing. It can be noticed that ingate expansion reduces the jetting effect; however, even with $10^{\circ}$ expansion, the jet is still present.

Figure 6, presenting a regular rectangular system with $H=25 \mathrm{~mm}$, shows completely different kinetics of the initial filling phase, compared to Fig. 5. Even with no tapering at all, the filling is laminar, achieving flow kinetics presented in 
Fig. 2(a). The change of geometric form of the system from circular to rectangular allowed to reduce the velocity of the metal entering the mold, thanks to the increased friction

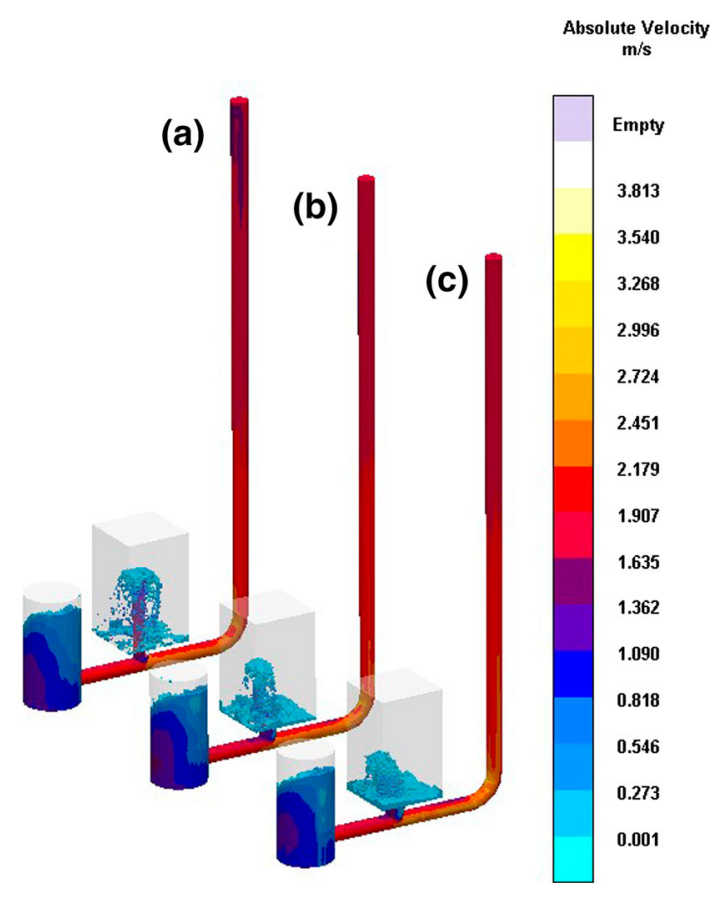

Fig. 5 Initial filling phase $(t=819 \mathrm{~ms})$ of variant: regular-circular- $H=25 \mathrm{~mm}$ - expansion angle (a) $0^{\circ}$, (b) $5^{\circ}$, and (c) $10^{\circ}$ between metal and the mold. The jetting effect was completely eliminated, even in case of non-expanded ingate. The metal velocity field during the pouring was noticeably more stationary in the system presented in Fig. 6, as compared to the system presented in Fig. 5, which, with less turbulent flow of the metal, can cause reduced possibility of oxide formation during the flow, and thus enhanced quality of the casting. Unfortunately, the software used for simulation of casting processes provides nearly no information about oxide biofilm formation

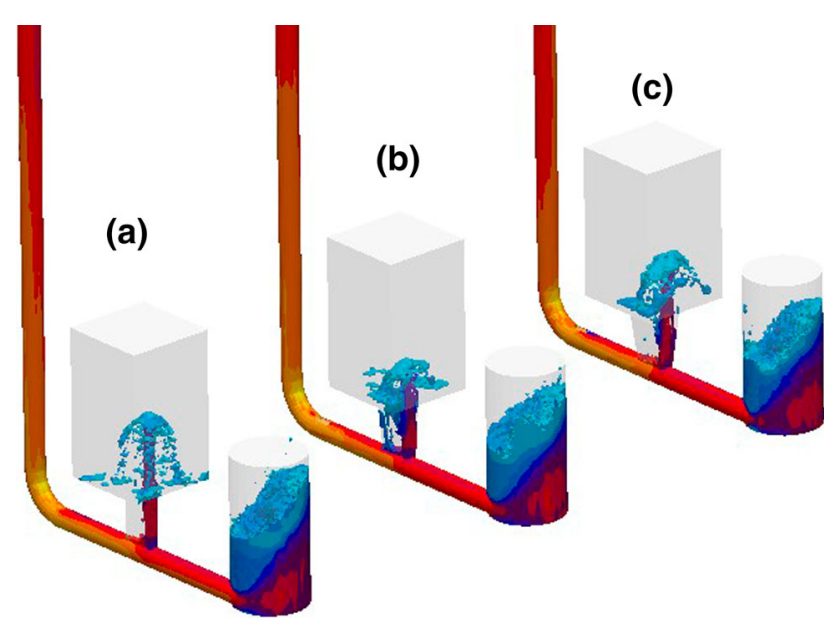

Fig. 7 Metal flowing only through a portion of the ingate $(t=630 \mathrm{~ms})$. Irregular - circular to rectangular- $H=50 \mathrm{~mm}-$ expansion angle (a) $0^{\circ}$, (b) $5^{\circ}$, and (c) $10^{\circ}$

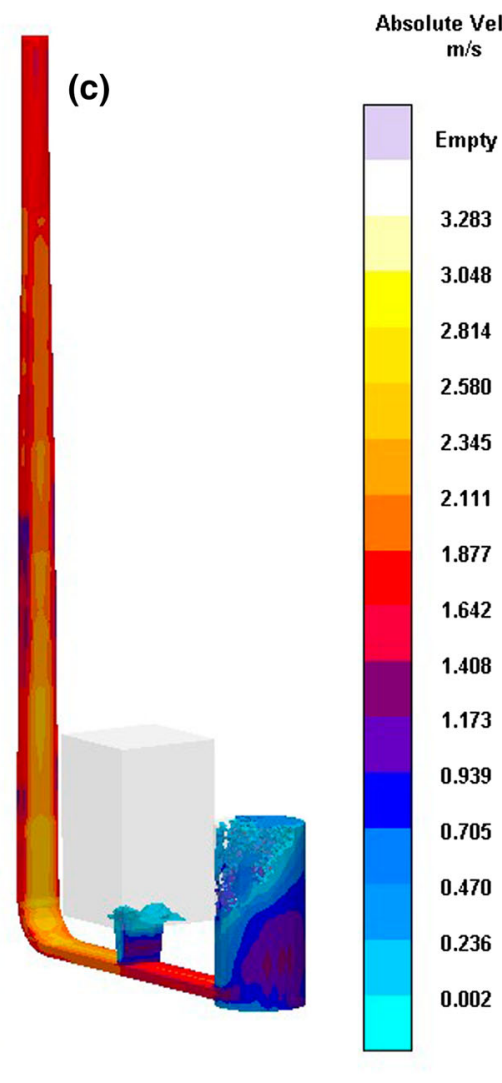

Fig. 6 Initial filling phase $(t=694 \mathrm{~ms})$ of variant: regular-rectangular- $H=25 \mathrm{~mm}$-expansion angle (a) $0^{\circ}$, (b) $5^{\circ}$, and (c) $10^{\circ}$ 
during the flow, neither their negative effect on the castings' quality nor the deleterious impact of bubbles.

The analysis of the irregular circular to rectangular systems simulation showed that, in those variants, with both $H$ values, the junction of the cross runner and the ingate created a pressure field that made the flow to take place only through a small portion of the ingate, thus increasing the velocity of streams, as shown in Fig. 7. Generally, this design should be avoided; however, there is a possibility to correctly utilize it by placing a foam filter tangentially to the cross runner and

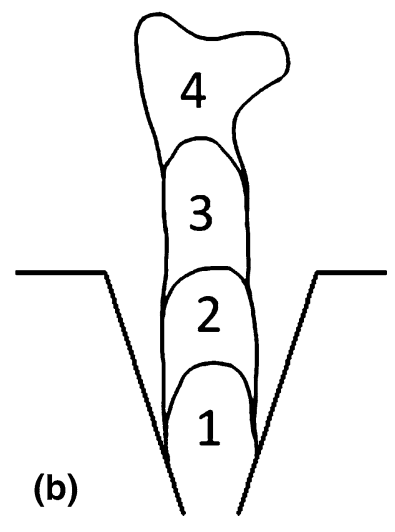

(b) flow of metal through the

Fig. 8 Proper (a) and improper

perpendicularly to the ingate. Thus, the kinetics of the flow in the system can be improved, as the filter would decrease the initial velocity of metal in the ingate and allow to obtain effect visible in Fig. 8(a).

Proper design of the ingate may be an amazing way of controlling the initial filling phase, as shown in Fig. 8(a). Metal flowing through the ingate should gradually and calmly fill all available spaces in the ingate, thus minimizing metal mixing and jetting. Improper expansion of the ingate may result in an effect shown in Fig. 8(b), ignoring the diffraction-like effect visible in Fig. 8(a), which is similar to flow types present in high-pressure die casting, and stream may detach from the ingates wall (the mold) exposing itself to formation of oxides and creating splashes and cold drops inside the mold. This effect must be avoided by all means, as it greatly deteriorates castings' quality. In authors' opinion, this effect is the reason of increased $v$ and $h$ with the highest expansion angle $\alpha=10^{\circ}$ in the regular rectangular system of $H=25 \mathrm{~mm}$ and the irregular circular into rectangular system of $H=50 \mathrm{~mm}$.

The spin trap was proven to be effective as the perfect tool to control filling parameters, similarly to the effective slag trap shown in Fig. 9, which presents the age and distribution of particles entering the mold in function of time. Not only it prevented the first portion of cooled and oxidized metal from entering the mold cavity, but it also trapped it inside due to the difference in density between oxides and cast steel. The presence of centrifugal force would force the oxides into the center of the trap and allow to successfully keep them there where they cannot negatively impact the castings' quality.

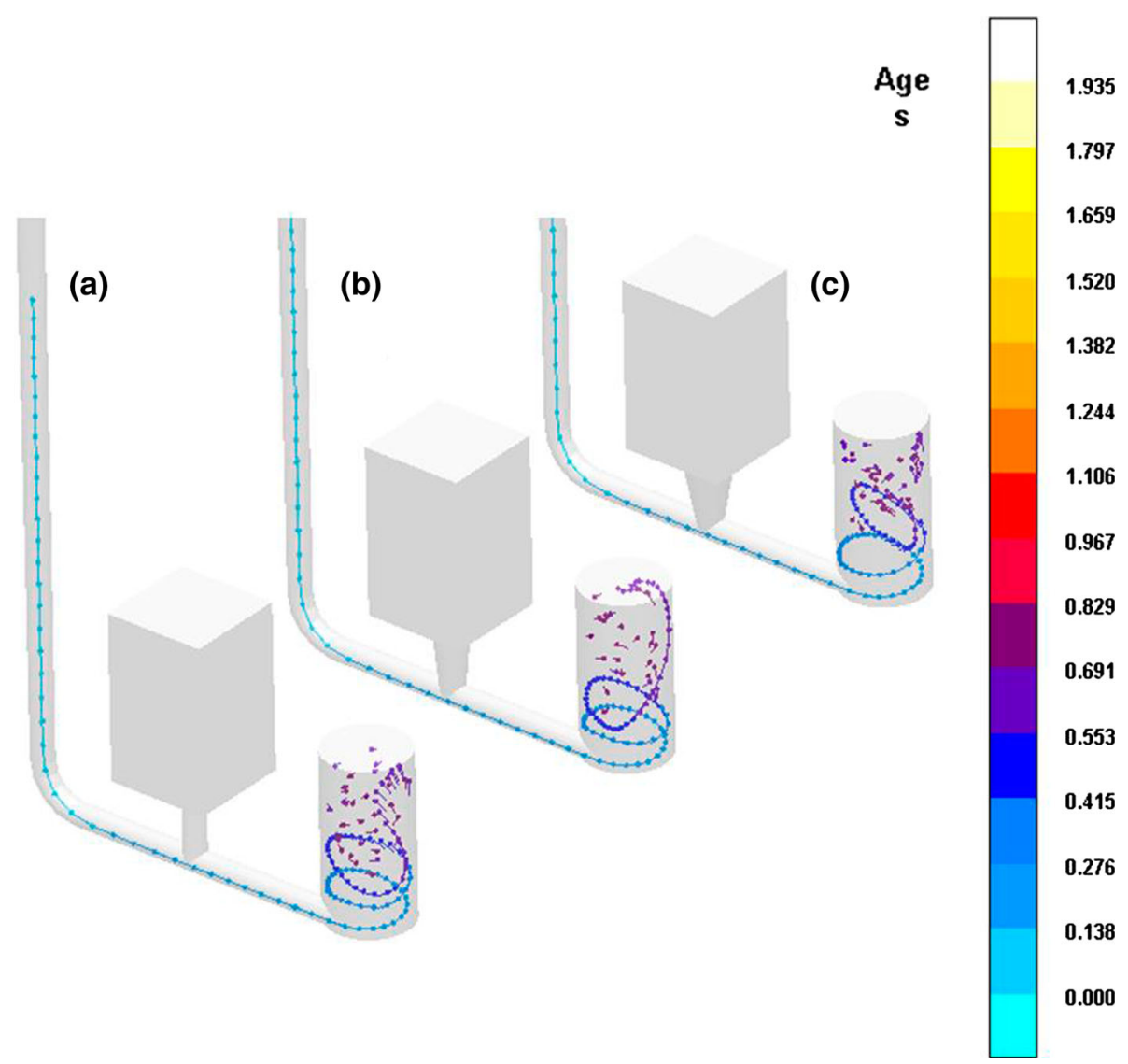

Fig. 9 First portion of cooled and oxidized metal entering the spin trap $(t=490 \mathrm{~ms})$. Regular - circular $-H=50 \mathrm{~mm}-$ expansion angle (a) $0^{\circ}$, (b) $5^{\circ}$, and (c) $10^{\circ}$ 


\section{Summary}

Experimental results of the gating system design optimization studies allowed to confirm that geometric form of gating system element has the key role in the initial filling of the mold. Conducted modeling shows the effectiveness of presented gating system designs in terms of reduction in velocity of metal entering the mold cavity and the height, and even the effect of metal jetting. The best results in terms of the lowest jet height and flow kinetics were obtained using regular rectangular systems and irregular rectangular into circular systems, but only with expansion. It should be borne in mind that improper expansion of the ingate may cause the detachment of the stream from the mold wall, which would cause reoxidation of the metal and degradation of castings' quality. Placing a foam filter tangentially to the cross runner and perpendicularly to the ingate can successfully improve the kinetics of the flow in the system. Further simulations will be conducted to examine different expansion angles $\alpha=2.5^{\circ}$ and $\alpha=7.5^{\circ}$, as well as the $(H)$ height in order to form a comprehensive relationship between those parameters, metals' $(v)$ velocity, and the $(h)$ height during the initial mold-filling phase, which would be helpful to technologists designing or optimizing manufacturing technologies of castings. Authors plan to verify simulation results with an analysis of examined molds filling in a real-life experiment. Further development of the simulation software would allow to account for the influence of oxide and bubble formation on the quality of castings.

\section{Open Access}

This article is distributed under the terms of the Creative Commons Attribution 4.0 International License (http://creativeco mmons.org/licenses/by/4.0/), which permits unrestricted use, distribution, and reproduction in any medium, provided you give appropriate credit to the original author(s) and the source, provide a link to the Creative Commons license, and indicate if changes were made.

\section{References}

1. M. Soinski, P. Kordas, and K. Skurka, Trends in the Production of Castings in the World and in Poland in the XXI, Century, Arch. Foundry Eng., 2016, 16(2), p 5-10

2. M. Holtzer, R. Danko, and S. Zymankowska-Kumon, The State of Art and Foresight of World's Casting Production, Metalurgija, 2014, 53(4), p 697-700

3. J. Danko and M. Holtzer, The State of Art and Foresight of World's Casting Production, Metalurgija, 2006, 45(4), p 333-340

4. D. Li, M. Sun, P. Wang, X. Kang, P. Fu, and Y. Li, Process Modelings and Simulations of Heavy Castings and Forgings, in Proceedings of the 11th International Conference on Numerical Methods in Industrial Forming Processes (NUMIFORM), 2013, p 81-94

5. E. Foglio, M. Gelfi, A. Pola, S. Goffelli, and D. Lusuardi, Fatigue Characterization and Optimization of the Production Process of Heavy Section Ductile Iron Castings, Int. J. Metalcast., 2017, 11(1), p 33-43
6. D. Yang, S. Li, F. He, W. Sung, J. Kao, and R. Chen, Twin Gating System Design for Typical Thin Wall Stainless Steel Castings Based on Fast Pouring Mechanism, Front. Mech. Eng. Mater. Eng. II, 2014, 457458, p 1657-1660 (Pts 1 and 2)

7. F. Hsu, M. Jolly, and J. Campbell, A Multiple-Gate Runner System for Gravity Casting, J. Mater. Process. Technol., 2009, 209(17), p 57365750

8. H. Zhou, L. Luo, Z. Shi, J. Dong, and W. Ma, Filling Pattern of Step Gating System in Lost Foam Casting Process and Its Application, Prog. Mater. Process., 2013, 602-604, p 1916-1921 (Pts 1-3)

9. K. Renukananda and B. Ravi, Multi-gate Systems in Casting Process: Comparative Study of Liquid Metal and Water Flow, Mater. Manuf. Process., 2016, 31(8), p 1091-1101

10. J. Jezierski, R. Dojka, K. Kubiak, and W. Zurek, Experimental Approach for Optimization of Gating System in Castings, in Metal 2016: 25th Anniversary International Conference on Metallurgy and Materials, 2016, p 104-109

11. M. Bruna, D. Bolibruchova, and R. Pastircak, Reoxidation Processes Prediction in Gating System by Numerical Simulation for Aluminium Alloys, Arch. Foundry Eng., 2017, 17(3), p 23-26

12. J. Sturm, G. Dieckhues, and S. Sikorski, Systematic Optimization of Aluminum Sand Casting Gating Systems, Trans. Am. Foundry Soc., 2012, 120, p 13-21

13. Y. Jiang, Y. He, Y. He, X. Qian, Y. Huang, L. Xu, W. Tian, and E. Mao, Analysis and Optimization on the Gating System of Aluminum Alloy Piston in Casting, Inf. Eng. Mech. Mater. Sci., 2011, 80-81, p 32-35 (Pts 1 and 2)

14. P. Huang and C. Lin, Computer-Aided Modeling and Experimental Verification of Optimal Gating System Design for Investment Casting of Precision Rotor, Int. J. Adv. Manuf. Technol., 2015, 79, p 997-1006

15. N. Ducic, R. Slavkovic, I. Milicevic, Z. Cojbasic, S. Manasijevic, and R. Radisa, Optimization of the Gating System for Sand Casting Using Genetic Algorithm, Int. J. Metalcast., 2017, 11(2), p 255-265

16. J. Fourie, J. Lelito, P. Zak, P. Krajewski, and W. Wolczynski, Numerical Optimization of the Gating System for an Inlet Valve Casting Made of Titanium Alloy, Arch. Metall. Mater., 2015, 60(3), p 2437-2446

17. J. Campbell, Cavitation in Liquid and Solid Metals: Role of Bifilms, Mater. Sci. Technol., 2015, 31(5), p 565-572

18. J. Campbell, Sixty Years of Casting Research, Metall. Mater. Trans. A, 2015, 46A(11), p 4848-4853

19. L. Camek, P. Lichy, I. Kroupova, J. Duda, J. Beno, M. Korbas, F. Radkovsky, and S. Bliznyukov, Effect of Cast Steel Production Metallurgy on the Emergence of Casting Defects, Metalurgija, 2016, 55(4), p 701-704

20. J. Campbell, Stop Pouring, Start Casting, Int. J. Metalcast., 2012, 6(3), p $7-18$

21. S.G. Acharya, J.A. Vadher, and K.D. Kothari, Evaluation of Critical Parameters for Sand Inclusion Defect in FNB Casting, Arch. Foundry Eng., 2017, 17(1), p 5-12

22. A. Modaresi, A. Safikhani, A. Noohi, N. Hamidnezhad, and S. Maki, Gating System Design and Simulation of Gray Iron Casting to Eliminate Oxide Layers Caused by Turbulence, Int. J. Metalcast., 2017, 11(2), p 328-339

23. Z. Ignaszak, Discussion on Usability of the Niyama Criterion for Porosity Predicting in Cast Iron Castings, Arch. Foundry Eng., 2017, 17(3), p 196-204

24. J. Campbell, The Consolidation of Metals: The Origin of Bifilms, J. Mater. Sci., 2016, 51(1), p 96-106

25. J. Campbell, Crack Populations in Metals, AIMS Mater. Sci., 2016, 3(4), p 1436-1442

Publisher's Note Springer Nature remains neutral with regard to jurisdictional claims in published maps and institutional affiliations. 